
\title{
25 Research Soure \\ Diversity and distribution of sulfate-reducing bacteria and its ecological effect in Shimen Realgar Mine
}

\author{
Xianbin Zhu (D 631286533@qq.com ) \\ Yangtze University \\ Liyuan Chen \\ Yangtze University \\ Hongzhong Pan \\ Yangtze University \\ Lei Wang \\ Yangtze University \\ Xun Zhang \\ Yangtze University \\ Dan Wang \\ Yangtze University
}

\section{Research Article}

Keywords: sulfate-reducing bacteria, drsAB genes, arsenate, realgar, Shimen Realgar Mine

Posted Date: February 24th, 2021

DOl: https://doi.org/10.21203/rs.3.rs-204743/v1

License: (1) This work is licensed under a Creative Commons Attribution 4.0 International License.

Read Full License 


\section{Abstract}

Microbial sulfate reduction, a vital mechanism for microorganisms living in anaerobic, sulfate-rich environments, is an essential aspect of the sulfur biogeochemical cycle. However, there has been no detailed investigation of the diversity and distribution of SRBs and its effect in Shimen Realgar Mine, which is characterized as a hot research area rich in sulfate. To elucidate this issue, soils sample from Shimen Realgar Mine were collected. Further, a total of 55 new or new-type dissimilatory sulfite reductase genes and 5 new families of DrsAB proteins were successfully identified, which demonstrate the rich and unique diversity of the sulfate reducing microbes in this environment. We also isolate a novel DSRP strain, Desulfotomaculum sp. JL90 from the soils, which can efficiently respiratory reduces sulfate and arsenate. JL90 also can promote the generation of yellow precipitations in the presence of multiple electron acceptors (both contain sulfate and $\mathrm{As}(\mathrm{V})$ in the cultures). Moreover, microbial community compositions also indicated the biogenesis contribution of SRBs to the Shimen realgar mine. The results of this study provided a new insight into the diversity and distribution of SRBs and its ecological effect in Shimen Realgar Mine.

\section{Introduction}

Microbial-catalyzed sulfate reduction can be performed as assimilatory and dissimilatory metabolisms (Marietou et al. 2018, Rodrigues et al. 2019). In the assimilatory process, sulfate reduction is incorporated to synthesize sulfur-containing cell components. In the second, sulfate-reducing organisms can utilize sulfate as terminal electron acceptor through an anaerobic respiration, along with organic compounds (formate, propionate, lactate, pyruvate, ethanol) or $\mathrm{H}_{2}$, methane, even phosphite as electron donors (Kushkevych et al. 2018). Among this electron transport chain, a conspicuous final production spills out, hydrogen sulfide $\left(\mathrm{H}_{2} \mathrm{~S}\right)$, which has been widely recognized as a poisonous chemical with a characteristic odor. The sulfate reducing microorganisms are widely distributed in different environments, including paddy soils, petroleum, oil reservoirs, soda lakes, marine sediments, acid mine drainage and thermal springs (Bao et al. 2012, Yan et al. 2018). Several enzymes are involved in this sulfate reduction process, such as ATP-sulfurylase, adenylylsulfate reductase and dissimilatory sulfite reductase. In addition to this, the reduction of sulfate to sulfur can be divided into several steps: ATP-sulfurylase drives the activation of sulfate into APS; adenosine 5'-phosphosulfate reductase (AprAB) catalyzes the transformation of APS to sulfite; the dissimilatory sulfite reductase (DrsAB) promotes the conversion of sulfite to sulfide (Li et al. 2019a, Rodrigues et al. 2019). The drsAB gene which encodes the DrsAB, had widely detected a range of SRB community structures, containing more than 20 different genera, such as Desulforibrio, Desulfomonas, Desulfobulbus, Desulfobacter, Desulfococcus, Desulfosarcina, Desulfonema, Desulfotomaculum and a genus Archaeoglobus within Archaea (Guan et al. 2013, Lu et al. 2017). Sulfate reduction mediated by microbes is often coupled to other interactions, such as fundamental biogeochemical processes, oil biodeterioration and biocorrosion, food spoilage, bioremediation the heavy metals and biodegradation of organic matter (George et al. 2008, Lai et al. 2020, Sheoran et al. 2010). Hence, the biotechnologies of SRBs could also be utilized in a variety of environmental treatments, such 
as microbial remediation of the heavy metals in wastewater or contaminated soils, dichlorination of organochlorines and repair of acid mine drainage (Hu et al. 2020, Shan et al. 2019, Zhang et al. 2016). However, previously published studies on the ecological effect of SRBs to the arsenic-sulfate coexist pollution system are limited.

As the largest source of natural realgar ore reserves in Asia with over 1500 years intensive exploiting histories, Shimen Realgar Mine was completely out of production in 2011 after a number of cases of Aspoisoning (Tang et al. 2016). The large amounts of As-contaminated wastes, such as soils, water, air, plants and animals have caused serious health risks to local resident. While previous researches mainly have focused on the arsenic biogeochemistry cycles, such as As oxidation, reduction and methylation, there have been far too little attention paid to the role of sulfur (Fan et al. 2018, Gao et al. 2017, Zhang et al. 2020). However, the fate of arsenic is influenced by abiotic or biological redox of sulfur, that can either mobilize or precipitate arsenic (Burton et al. 2013, Edwardson and Hollibaugh 2017, Zhu et al. 2017). Moreover, the soil of this place also contains a large amount of sulfur which occupied $0.7-0.8 \%$ (Chen et al. 2017). Therefore, it's necessary to investigate the diversity and distribution of SRBs in Shimen Realgar Mine and its environmental effects.

In this context, the main issues addressed in this work are to: 1) investigate the diversity and distribution of SRBs in Shimen Realgar Mine; 2) figure out the ecological effect of SRBs to the arsenic-sulfate coexist pollution system.

\section{Materials And Methods}

\section{Sampling and geochemical analysis}

Soil samples were derived from the surface layer $(0-20 \mathrm{~cm})$ of an abandoned tailing realgar (As4S4) mine area located in Baiyun village, Changde City, Hunan Province, China in July 2020. The site was located at $29^{\circ} 38^{\prime} 50^{\prime \prime}, 111^{\circ} 2^{\prime} 20^{\prime \prime}$. After sampling, the soil samples were carefully mixed, sealed and stored in a sterile polyethylene boxes $\left(4^{\circ} \mathrm{C}\right)$ and transported to the laboratory immediately. Certain soil samples were naturally air-dried, crushed, homogenized, and passed through a $2 \mathrm{~mm}$ nylon sieve for geochemical properties analysis. Other soils were stored for the subsequent batch microcosm assays. Total As, soluble As, sulfate, total organic carbon and other characterizations were analyzed as described previously and the results were showed in Table 1 (Yang et al. 2018).

\section{DNA extraction and sequence analysis of dissimilatory sulfite reductase (dsrAB) genes from the soils}

Total DNA was extracted from a $0.5 \mathrm{~g}$ soil sample using the FastDNA ${ }^{\circledR}$ SPIN kit(MP bio, USA) for soil following the manufacturer's protocol (Bao et al. 2021). The concentration and quality of extracted DNA were detected using NanoDrop 2000 spectrophotometer. The DSRp2060F(5'-

CAACATCGTYCAYACCCAGGG-3') and DSR4R(5'-GTGTARCAGTTDCCRCA-3') primers was chosen to amply the genes of $d r s A B$ with PCR reactions (Besaury et al. 2012, Geets et al. 2006). PCR conditions consisted of a initial denaturation step of $94^{\circ} \mathrm{C}$ for $4 \mathrm{~min}$, followed by 35 cycles of $94^{\circ} \mathrm{C}$ for $1 \mathrm{~min}, 55^{\circ} \mathrm{C}$ 
for $1 \mathrm{~min}$, and $72^{\circ} \mathrm{C}$ for $1 \mathrm{~min}$ with a final extension at $72^{\circ} \mathrm{C}$ for $10 \mathrm{~min}$. Amplified PCR products were separated with a DNA electrophoresis. DNA bands were cut out, and DNA was extracted and purified using QIAquick Gel Extraction Kit, and then cloned into the pMD19-T vector for sequencing as described previously. The obtained DNA sequences were analyzed with BLAST server and MEGA 6.0 software.

\section{Isolation of a novel DSRP strain from the arsenic-contaminated soils}

A modified cultured medium was applied in these microbial enrichment experiments. The medium consists of (per liter of dd water, pH6.8): $\mathrm{NH}_{4} \mathrm{Cl} 1.0 \mathrm{~g}, \mathrm{Na}_{2} \mathrm{SO}_{4} 1.0 \mathrm{~g}, \mathrm{KH}_{2} \mathrm{PO}_{4} 0.65 \mathrm{~g}, \mathrm{CaCl}_{2} 0.05 \mathrm{~g}$, sodium lactate $3.5 \mathrm{~g}$, yeast extract, vitamin $\mathrm{C} 0.1 \mathrm{~g}$ and $\mathrm{Fe}\left(\mathrm{NH}_{4}\right)_{2}\left(\mathrm{SO}_{4}\right)_{2} 6 \mathrm{H}_{2} \mathrm{O} 1.2 \mathrm{~g}$ (as an indicator). Approximately $1.5 \mathrm{~g}$ of soil samples was added into $10.0 \mathrm{~mL}$ anoxic sterile medium as described previously. Standard anaerobic incubations were performed at $30^{\circ} \mathrm{C}$ for enrichment. When the color of the medium was converted into dark (the best proof of the positive growth of SRB), about $0.5 \mathrm{~mL}$ of cultures was transferred into $10.0 \mathrm{~mL}$ of the same fresh medium for second-round enrichment. This step was repeated several rounds. The enrichment culture was diluted into different gradient concentrations and used the agar shake tube technique for isolating single bacterial strains under strict anaerobic condition (Dias et al. 2008).

\section{Cloning, sequencing and data analysis of bacterial 16S rRNA and dsrAB genes}

Genomic DNA was extracted using a simple boiling method described by Miyamoto. Briefly, several bacterial cells were collected into $1.0 \mathrm{~mL}$ centrifuge tubes, boiled at $100^{\circ} \mathrm{C}$ for 15 mins, and centrifuged at $5000 \mathrm{~min}^{-1}$ for 2 mins. The $16 \mathrm{~S}$ rRNA gene was amplified and sequenced using universal bacterial primer set 27F/1492R (Kim et al. 2020). The DrsAB of dissimilatory sulfite reductase protein were cloned, sequenced and analyzed using the primer set DSRp2060/DSR4R described above. Dendrograms analyses of the obtained DrsAB protein and bacterial 16S rRNA gene sequence with 1,000 replicated bootstrap were constructed using the neighbor-joining method.

\section{Functional characterization of the novel cultivable isolate}

The bacterial anaerobic functional characterization experiments were performed via addition with different electron acceptors, such as $\mathrm{As}(\mathrm{V}), \mathrm{SO}_{4}{ }^{2-}$ and combined electron acceptors of $\mathrm{As}(\mathrm{V})$ and $\mathrm{SO}_{4}{ }^{2-}$. $\mathrm{A}$ certain amount of JL1 cells were inoculated into $10.0 \mathrm{~mL}$ of modified MMS medium containing $10.0 \mathrm{mM}$ lactate acting as the sole electron donor, and $1.0 \mathrm{mM} \mathrm{SO}_{4}{ }^{2-}, 1.0 \mathrm{mM} \mathrm{As}(\mathrm{V})$ or the $1.0 \mathrm{mM}$ combined electron acceptors of $\mathrm{As}(\mathrm{V})$ and $\mathrm{SO}_{4}{ }^{2-}$. Strict anaerobic incubations were performed at $30^{\circ} \mathrm{C}$ and briefly shaken once a day. At an interval of half day, about $0.5 \mathrm{~mL}$ of the culture mixture was taken for measuring the concentration of arsenic and sulfur species.

\section{Determination of the microbial community structures}

Total DNA of the soil sample was PCR amplified with the primer pair 341F/806R for the V3-V4 hypervariable regions of the 16S rRNA gene as described elsewhere (Li et al. 2019b). Then the high- 
throughput sequencing was performed on the MiSeq platform.

\section{Results}

\section{Geochemical characterizations}

The physical properties of the soils are presented in Table1. The tailing soil samples of the Shimen Realgar Mine were reddish brown in appearance. The soils $\mathrm{pH}$ value was 6.72, indicating the weakly acidic of these soils. As the largest deposit of realgar ore $\left(\mathrm{As}_{4} \mathrm{~S}_{4}\right)$ in China, the soils of the Shimen Realgar Mine contains high concentrations of sulfate $(350 \mathrm{mg} / \mathrm{kg})$ and total arsenic $(1345.31 \mathrm{mg} / \mathrm{kg})$ According to the national soil quality standard of China (GB15618-2018), the total As concentration of the sampling site exceeded 40 folds of the concentration grade II $(30 \mathrm{mg} / \mathrm{kg} .6<\mathrm{pH} \leq 7.5)$ in agricultural land, revealing serious risks to the environment and human health (Wan et al. 2017, Wu et al. 2016). Moreover, the sample also had a relatively high abundance of TOC $(59.40 \mathrm{mg} / \mathrm{g})$, which provided a suitable environment for the growth and reproduction of microorganisms.

\section{Unique molecular diversity of drsAB genes}

There has been little quantitative analysis of the diversity of the sulfate reducing genes in the microbial communities of the Shimen Realgar Mine. The phylogenetic affiliation of $\operatorname{drs} A B$ gene sequences is presented in Fig.1. Dissimilatory sulfite reductase was a key enzyme for sulfate reducers, which catalyzed the energy-generation step during anaerobic respiration of sulfite. The alpha and beta subunit of dissimilatory sulfite reductase ( $d r s A$ and $d r s B$ ) has been used as a maker to detect sulfate reducers in different ecosystems. We obtained 65 new or new-type dissimilatory sulfite reductase genes by amplifying, cloning and sequencing its from the total genomic DNA of the soil sample. Phylogenetic relationships of the $d r s A B$ gene sequences revealed a rich and unique diversity compared to the other known DrsAB proteins from bacteria, archaea, fungi and animal. We found that these new DrsABs from the soils share $66.18-98.33 \%$ sequences identities to those deposited in GeneBank protein database.

It is well established from a variety of studies, that if a group of ArsABs from an independent cluster in the phylogenetic tree, and they share less than $60 \%$ maximal homology with other known DrsAB proteins, we classified them as a new family of DrsABs. According to this rule, we successfully identified 5 new families of DrsAB proteins from the soils: family 1(OTU1, OTU02, OTU09, OTU11, OTU12, OTU13, OTU15, OTU17, OTU18, OTU20, OTU22, OTU27, OTU29, OTU30, OTU32, OTU36, OYU37, OTU38, OTU42, OTU44, OTU46, OTU51, OTU52, OTU53, OTU54, OTU57, OUT58, OTU60) family2(OTU61, OTU62, OTU65), family3(OTU16, OTU24, OTU26, OTU39, OTU56, OTU59), family4(OTU08, OTU10, OTU19, OTU21, OTU23, OTU25, OTU34, OTU40, OTU47, OTU50, OTU55), and family5(OTU03, OTU04, OTU05, OTU06, OTU07, OTU14, OTU31, OTU33, OTU41, OTU45, OTU48, OTU63, OTU64). Specifically, family 1 and family 2 are closely associated with the uncultured bacterium clone (MF46488.1, MF068426.1 and MF068557.1). Family 3 was closely related to the DrsB proteins (ALA001000371.1 and XM014089040.1) from Desulfovibrio magneticus str. Maddingley MBC34 and cultured fungi Trichoderma atroviride IMI 2060040, 
separately. New family 4 is closely related to the DrsB protein (ABDG02000001.1) from Trichoderma atroviride IMI 2060040. New family 5 is closely related to the uncultured bacterium clone (KT122053.1 and KT122078.1) and DrsB Sphaeroforma arctica JP610 (KQ242215.1).

These findings demonstrate the rich and unique diversity of the sulfate reducing microbes in the soils of Shimen Realgar Mine.

\section{Phylogenetic features of the bacterial strain JL1}

To further reveal the functional characterization and its environmental effects of the sulfate reducing bacteria in the Shimen Realgar Mine, we isolated a representative dissimilatory sulfate reducing bacterium using microbial enrichment technique, which was referred to as JL01. 16S rRNA gene phylogenetic analysis revealed that the novel isolate belonged to the Firmicutes and shared the closest relatives was Desulfotomaculum sp.GY-2(HQ827821.1) with 98.72\% sequence similarity (Fig2.a). The phylogenetic dendrogram also illustrates JL01 fell into the same cluster with high bootstrap value within Desulfotomaculum and was thus referred to as Desulfotomaculum sp.JL1.

The $d r s B$ gene sequences of the present isolate were deposited in GeneBank under the accession number of MF2424512 and MF2424527, were identified as JL1-Drsb-1 and JL1-Drsb-2. According to the phylogenetic dendrogram shown $d r s B$ gene sequences comparison in Fig.2.b, 11 reference strains were chosen to display the sequence similarity (93.09-95.80\%). The result illustrated that JL0-Drsb-1 shares 95.80\%, 95.51\%, 94.44\% and 93.62\% sequence identities to those of Desulfovibrio sp. sul5, Desulfovibrio burkinensis strain DSM 6830, Desulfovibrio fructosivorans, and Desulfovibrio aerotolerans, respectively. These results showed that JL01 possesses new dissimilatory sulfate reductases, and it also can be inferred this isolate is a novel DRSB strain.

\section{Anaerobic reduction activities of $J L 1$}

Fig.3 illustrates the sulfate and arsenate-respiring activities of Desulfotomaculum sp. JL01. As shown in Fig.3.a, JL90 is highly effective in sulfate reduction under anaerobic condition. It takes only 5 days sulfate can be completely converted to sulphion catalyzed by JL90 in MMM medium (without sulfate) containing $2.0 \mathrm{mM}$ sulfate and $10.0 \mathrm{mM}$ sodium lactate. JL90 also has apparent activity to reduce As(V). As shown in Fig.3b, in the presence of $1.5 \mathrm{mM} \mathrm{As}(\mathrm{V})$, the $\mathrm{As}(\mathrm{V})$ reduction efficiency is slow at beginning using lactate as the sole electron donor under anaerobic condition. However, after 4 days of incubation, $1.5 \mathrm{mM}$ As(V) was completely transformed into As(III).

To further explore the reduction abilities of bacterial cells in the presence of multiple electron acceptors, we performed the bacterial reduction assay containing $2.0 \mathrm{mM}$ sulfate and $1.5 \mathrm{mM} \mathrm{As}(\mathrm{V})$ as electron acceptors and lactate as the sole electron donor under anaerobic condition. As shown in Fig.3c, when sulfate and $\mathrm{As}(\mathrm{V})$ were added to the cultures, compared to Fig 3a, the sulfate reduction ability is more efficient than that achieved in only presence of sulfate. After 4 days of incubation, $2.0 \mathrm{mM}$ sulfate can be fully reduced. Moreover, compared to Fig3b, the $\mathrm{As}(\mathrm{V})$ reduction ability is much slower than that only 
addition into $\mathrm{As}(\mathrm{V})$; after 4 days, only half of $\mathrm{As}(\mathrm{V})$ converted to $\mathrm{As}(\mathrm{III})$. After 10 days of incubation, a significant amount of yellow precipitations were generated in the cultured. This phenomenon suggests that microorganisms can drive the reduction of $\mathrm{As}(\mathrm{V})$ and $\mathrm{SO}_{4}{ }^{2-}$, and can effectively promote the formation of precipitation, which also hints the biogenesis of the realgar mine in Shimen.

\section{Unique microbial community compositions of the Shimen realgar soils}

The microbial community compositions in the Shimen realgar on phylum and genus level were showed in Fig4. At the phylum level, the main phylum in average including Proteobacteria ( $81.24 \%$ of the total microbial communities), Bacteriodetes (the relative abundance of $6.39 \%$ ), Others (4.02\%), Parcubacteria (3.89\%), Firmicutes $(2.11 \%)$ and Actinobacteria (1.29\%) were dominant in Shimen realgar soil; this microbial community compositions are relatively consistent with previous reports of the site. At the genus level, fourteen genera were most abundant, encompassing $70.13 \%$ of the total, Other (the relative abundance of $28.89 \%$ ), norank f Moraxellaceae (23.59\%), Thiobacillus (16.29\%), Sulfurifustis $(7.02 \%)$, Hydrogenophaga (4.42\%), norank $f$ Hydrogenophilaceae (3.98\%), Arenimonas (2.86\%), norank $p$ Parcubacteria (2.62\%), Fluviicola (2.32\%), norank o Alphaproteobacteria Incertae Sedis (1.83\%), norank $f$ Nitrosomonadaceae (1.52\%), Sediminibacterium (1.31\%), Sphingomonas (1.23\%) and norank $f$ Rhodospirllaceae (1.14\%); and this site also contains typical sulfur-metabolizing bacteria, such as Surfurifustis, Desulfurivibrio, Thiomonas, Sulfuricella and Thiobacillus.

\section{Discussion}

\section{Unique geochemistry characteristics and microbial community structures}

The Shimen realgar mine in China has been exploited for approximately 1500 years and was the largest source of realgar $\left(\mathrm{As}_{4} \mathrm{~S}_{4}\right)$ ore in Asia (Peng et al. 2019). Hence, the soils contain extremely high concentrations of arsenic and sulfate. However, previous researches have only focused on the microbialcatalyzed arsenic metabolism, and have found that microorganisms here have the strong ability to drive As(III)-oxidation, As(V)-reduction and As-methylation. In this study, based on the geochemistry characteristics and microbial community structures, we focused on investigation the diversity and activities of sulfate-reducing microorganisms from the tailings. Compared to other arsenic-contaminated or sulfate-contaminated sites, this area had unique microbial communities, which were attributed by the unique geochemistry. These findings also demonstrate the rich and unique diversity of the sulfate reducing microbes in the soils of Shimen Realgar Mine, which also totally different from the other researches.

\section{Conceptual model for the ecological effect of sulfatereducing bacteria to the Shimen Realgar Mine.}

Realgar contains over $90 \%$ tetra-arsenic tetra-sulfide $\left(\mathrm{As}_{4} \mathrm{~S}_{4}\right)$, was commonly used as a drug to treat diseases in ancient China, India and other countries for thousands of years (Wu et al. 2017). In recent years, realgar also has been proven to be effective clinical treatment to various forms of cancer in vivo and in vitro. Compared with the disadvantages of traditional methods, such as low solubility in water, 
poor gastrointestinal absorption, high toxicity and low bioavailability of realgar, microbial leaching technology can significantly improve the solubility and bioavailability of realgar, and also has high efficiency, ecologically safe, low cost and other advantages. In a previous study, Chen found A.ferrooxidans can effectively bioleach realgar in different environment (Chen et al. 2011). However, our research also found this novel DSRP strain JL1 can also effectively promote the formation of the yellow precipitation, and a conceptual model for the ecological effect of sulfate-reducing bacteria to the Shimen Realgar Mine (Fig.5).

\section{Can this sulfate reducing bacterium be used for bioremediation of As and sulfate-contaminated water?}

Using SRB as a biological treatment for AMD remediation has gained extensive attention (Kefeni et al. 2017, Sánchez-Andrea et al. 2014). Several researches have approved SRB as an effective AMD treatment option for the ability to produce the alkalinity and remove the heavy metals. However, our research provides a new insight into the SRB used for bioremediation of As and sulfate-contaminated water. Meanwhile, bioleaching of realgar from the soil using SRB also has a promising industrial potential.

\section{Declarations}

Ethical Approval: This article does not contain any studies with human participants or animals performed by any of the author.

Consent to Participate: All participants gave informed consent at enrollment.

Consent to Publish: All participants gave final approval for publication.

Authors Contributions: Hongzhong Pan and Xianbin Zhu designed research; Xianbin Zhu performed research; Xianbin Zhu and Liyuan Chen analyzed data; Xianbin Zhu wrote the manuscript. Lei Wang, Xun Zhang and Dan Wang revised and reviewed the drafts.

Funding: This work is supported by the Engineering Research Center of Ecology and Agricultural Use of Wetland, Ministry of Education (no. KFT201903).

Competing Interests: The authors declare that they have no conflict of interest.

Data availability: The datasets used and/or analyzed during the current study are available from the corresponding author on reasonable request.

\section{References}

Bao, P., Hu, Z.-Y., Wang, X.-J., Chen, J., Ba, Y.-X., Hua, J., Zhu, C.-Y., Zhong, M. and Wu, C.-Y. (2012) Dechlorination of $p, p^{\prime}-D D T s$ coupled with sulfate reduction by novel sulfate-reducing bacterium Clostridium sp. BXM. Environmental Pollution 162, 303-310. 
Bao, Y., Jin, X., Guo, C., Lu, G. and Dang, Z. (2021) Sulfate-reducing bacterial community shifts in response to acid mine drainage in the sediment of the Hengshi watershed, South China. Environmental Science and Pollution Research 28(3), 2822-2834.

Besaury, L., Ouddane, B., Pavissich, J.P., Dubrulle-Brunaud, C., González, B. and Quillet, L. (2012) Impact of copper on the abundance and diversity of sulfate-reducing prokaryotes in two chilean marine sediments. Mar Pollut Bull 64(10), 2135-2145.

Burton, E.D., Johnston, S.G., Kraal, P., Bush, R.T. and Claff, S. (2013) Sulfate availability drives divergent evolution of arsenic speciation during microbially mediated reductive transformation of schwertmannite. Environ Sci Technol 47(5), 2221-2229.

Chen, P., Yan, L., Leng, F., Nan, W., Yue, X., Zheng, Y., Feng, N. and Li, H. (2011) Bioleaching of realgar by Acidithiobacillus ferrooxidans using ferrous iron and elemental sulfur as the sole and mixed energy sources. Bioresour Technol 102(3), 3260-3267.

Chen, Z., Wang, Y., Jiang, X., Fu, D., Xia, D., Wang, H., Dong, G. and Li, Q. (2017) Dual roles of AQDS as electron shuttles for microbes and dissolved organic matter involved in arsenic and iron mobilization in the arsenic-rich sediment. Science of The Total Environment 574, 1684-1694.

Dias, M., Salvado, J.C., Monperrus, M., Caumette, P., Amouroux, D., Duran, R. and Guyoneaud, R. (2008) Characterization of Desulfomicrobium salsuginis sp. nov. and Desulfomicrobium aestuarii sp. nov., two new sulfate-reducing bacteria isolated from the Adour estuary (French Atlantic coast) with specific mercury methylation potentials. Systematic and Applied Microbiology 31(1), 30-37.

Edwardson, C.F. and Hollibaugh, J.T. (2017) Metatranscriptomic analysis of prokaryotic communities active in sulfur and arsenic cycling in Mono Lake, California, USA. ISME J 11(10), 2195-2208.

Fan, L., Zhao, F., Liu, J. and Frost, R.L. (2018) The As behavior of natural arsenical-containing colloidal ferric oxyhydroxide reacted with sulfate reducing bacteria. Chemical Engineering Journal 332, 183-191.

Gao, P., Zeng, X., Bai, L., Wang, Y., Wu, C., Duan, R. and Su, S. (2017) As(V) Resistance and Reduction by Bacteria and Their Performances in As Removal from As-Contaminated Soils. Curr Microbiol 74(9), 11081113.

Geets, J., Borremans, B., Diels, L., Springael, D., Vangronsveld, J., van der Lelie, D. and Vanbroekhoven, K. (2006) DsrB gene-based DGGE for community and diversity surveys of sulfate-reducing bacteria. J Microbiol Methods 66(2), 194-205.

George, J., Purushothaman, C.S. and Shouche, Y.S. (2008) Isolation and characterization of sulphatereducing bacteria Desulfovibrio vulgaris from Vajreshwari thermal springs in Maharashtra, India. World Journal of Microbiology and Biotechnology 24(5), 681-685. 
Guan, J., Xia, L.-P., Wang, L.-Y., Liu, J.-F., Gu, J.-D. and Mu, B.-Z. (2013) Diversity and distribution of sulfatereducing bacteria in four petroleum reservoirs detected by using $16 \mathrm{~S}$ rRNA and dsrAB genes. International Biodeterioration \& Biodegradation 76, 58-66.

$\mathrm{Hu}, \mathrm{K} ., \mathrm{Xu}, \mathrm{D}$. and Chen, Y. (2020) An assessment of sulfate reducing bacteria on treating sulfate-rich metal-laden wastewater from electroplating plant. Journal of Hazardous Materials 393, 122376.

Kefeni, K.K., Msagati, T.A.M. and Mamba, B.B. (2017) Acid mine drainage: Prevention, treatment options, and resource recovery: A review. Journal of Cleaner Production 151, 475-493.

Kim, Y.J., Yang, J.-A., Lim, J.K., Park, M.-J., Yang, S.-H., Lee, H.S., Kang, S.G., Lee, J.-H. and Kwon, K.K. (2020) Paradesulfovibrio onnuriensis gen. nov., sp. nov., a chemolithoautotrophic sulfate-reducing bacterium isolated from the Onnuri vent field of the Indian Ocean and reclassification of Desulfovibrio senegalensis as Paradesulfovibrio senegalensis comb. nov. Journal of Microbiology 58(4), 252-259.

Kushkevych, I., Kováč, J., Vítězová, M., Vítěz, T. and Bartoš, M. (2018) The diversity of sulfate-reducing bacteria in the seven bioreactors. Archives of Microbiology $200(6), 945-950$.

Lai, R., Li, Q., Cheng, C., Shen, H., Liu, S., Luo, Y., Zhang, Z. and Sun, S. (2020) Bio-competitive exclusion of sulfate-reducing bacteria and its anticorrosion property. Journal of Petroleum Science and Engineering $194,107480$.

Li, J., Cai, M.-H., Miao, Y., Luo, G., Li, W.-T., Li, Y. and Li, A.-M. (2019a) Bacterial community structure and predicted function in an acidogenic sulfate-reducing reactor: Effect of organic carbon to sulfate ratios. Bioresour Technol 293, 122020.

Li, X., Xiao, H., Zhang, W., Li, Y., Tang, X., Duan, J., Yang, Z., Wang, J., Guan, F. and Ding, G. (2019b) Analysis of cultivable aerobic bacterial community composition and screening for facultative sulfatereducing bacteria in marine corrosive steel. Journal of Oceanology and Limnology 37(2), 600-614.

Lu, S., Han, S., Du, Y., Liu, H., Nie, H., Luo, X., Huang, Q. and Chen, W. (2017) The shift of sulfate-reducing bacterial communities from the upland to the paddy stage in a rapeseed-rice rotation system, and the effect from the long-term straw returning. Applied Soil Ecology 124.

Marietou, A., Roy, H., Jorgensen, B.B. and Kjeldsen, K.U. (2018) Sulfate Transporters in Dissimilatory Sulfate Reducing Microorganisms: A Comparative Genomics Analysis. Front Microbiol 9, 309.

Peng, H., Ji, X., Jian, Z., Wei, W., Jiapei, C., Bocharnikova, E. and Matichenkov, V. (2019) Effect of Si on As Speciation and Distribution in Rice near the Shimen Realgar Mine. Mine Water and the Environment 38(4), 808-816.

Rodrigues, C., Núñez-Gómez, D., Silveira, D.D., Lapolli, F.R. and Lobo-Recio, M.A. (2019) Chitin as a substrate for the biostimulation of sulfate-reducing bacteria in the treatment of mine-impacted water (MIW). Journal of Hazardous Materials 375, 330-338. 
Sánchez-Andrea, I., Sanz, J.L., Bijmans, M.F.M. and Stams, A.J.M. (2014) Sulfate reduction at low pH to remediate acid mine drainage. Journal of Hazardous Materials 269, 98-109.

Shan, S., Guo, Z., Lei, P., Wang, Y., Li, Y., Cheng, W., Zhang, M., Wu, S. and Yi, H. (2019) Simultaneous mitigation of tissue cadmium and lead accumulation in rice via sulfate-reducing bacterium. Ecotoxicol Environ Saf 169, 292-300.

Sheoran, A.S., Sheoran, V. and Choudhary, R.P. (2010) Bioremediation of acid-rock drainage by sulphatereducing prokaryotes: A review. Minerals Engineering 23(14), 1073-1100.

Tang, J., Liao, Y., Yang, Z., Chai, L. and Yang, W. (2016) Characterization of arsenic serious-contaminated soils from Shimen realgar mine area, the Asian largest realgar deposit in China. Journal of Soils and Sediments 16(5), 1519-1528.

Wan, X., Dong, H., Feng, L., Lin, Z. and Luo, Q. (2017) Comparison of three sequential extraction procedures for arsenic fractionation in highly polluted sites. Chemosphere 178, 402-410.

Wu, F., Wang, J.-T., Yang, J., Li, J. and Zheng, Y.-M. (2016) Does arsenic play an important role in the soil microbial community around a typical arsenic mining area? Environmental Pollution 213, 949-956.

Wu, Y., Zhou, X.-y., Lei, M., Yang, J., Ma, J., Qiao, P.-w. and Chen, T.-b. (2017) Migration and transformation of arsenic: Contamination control and remediation in realgar mining areas. Applied Geochemistry 77, 4451.

Yan, J., Zhong, K., Wang, S., Chen, Z., Hu, H., Jian, Z., Wen, H. and Zhang, H. (2018) Carbon metabolism and sulfate respiration by a non-conventional Citrobacter freundii strain SR10 with potential application in removal of metals and metalloids. International Biodeterioration \& Biodegradation 133, 238-246.

Yang, F., Xie, S., Wei, C., Liu, J., Zhang, H., Chen, T. and Zhang, J. (2018) Arsenic characteristics in the terrestrial environment in the vicinity of the Shimen realgar mine, China. Science of The Total Environment 626, 77-86.

Zhang, G., Ouyang, X., Li, H., Fu, Z. and Chen, J. (2016) Bioremoval of antimony from contaminated waters by a mixed batch culture of sulfate-reducing bacteria. International Biodeterioration \& Biodegradation 115, 148-155.

Zhang, M., Li, Z., Häggblom, M.M., Young, L., He, Z., Li, F., Xu, R., Sun, X. and Sun, W. (2020) Characterization of Nitrate-Dependent As(III)-Oxidizing Communities in Arsenic-Contaminated Soil and Investigation of Their Metabolic Potentials by the Combination of DNA-Stable Isotope Probing and Metagenomics. Environ Sci Technol 54(12), 7366-7377.

Zhu, Y.G., Xue, X.M., Kappler, A., Rosen, B.P. and Meharg, A.A. (2017) Linking Genes to Microbial Biogeochemical Cycling: Lessons from Arsenic. Environ Sci Technol 51(13), 7326-7339. 


\section{Table}

Table 1 Geochemical parameters of the tailing soils sample.

\begin{tabular}{|llllll|}
\hline & $\mathrm{pH}$ & $\mathrm{TOC}(\mathrm{mg} / \mathrm{g})$ & Total As $(\mathrm{mg} / \mathrm{kg})$ & Soluble As $(\mathrm{mg} / \mathrm{kg})$ & $\mathrm{SO}_{4}{ }^{2-}(\mathrm{mg} / \mathrm{kg})$ \\
\hline sample & 6.72 & 59.40 & 1345.31 & 20.61 & 350 \\
\hline
\end{tabular}

Figures 


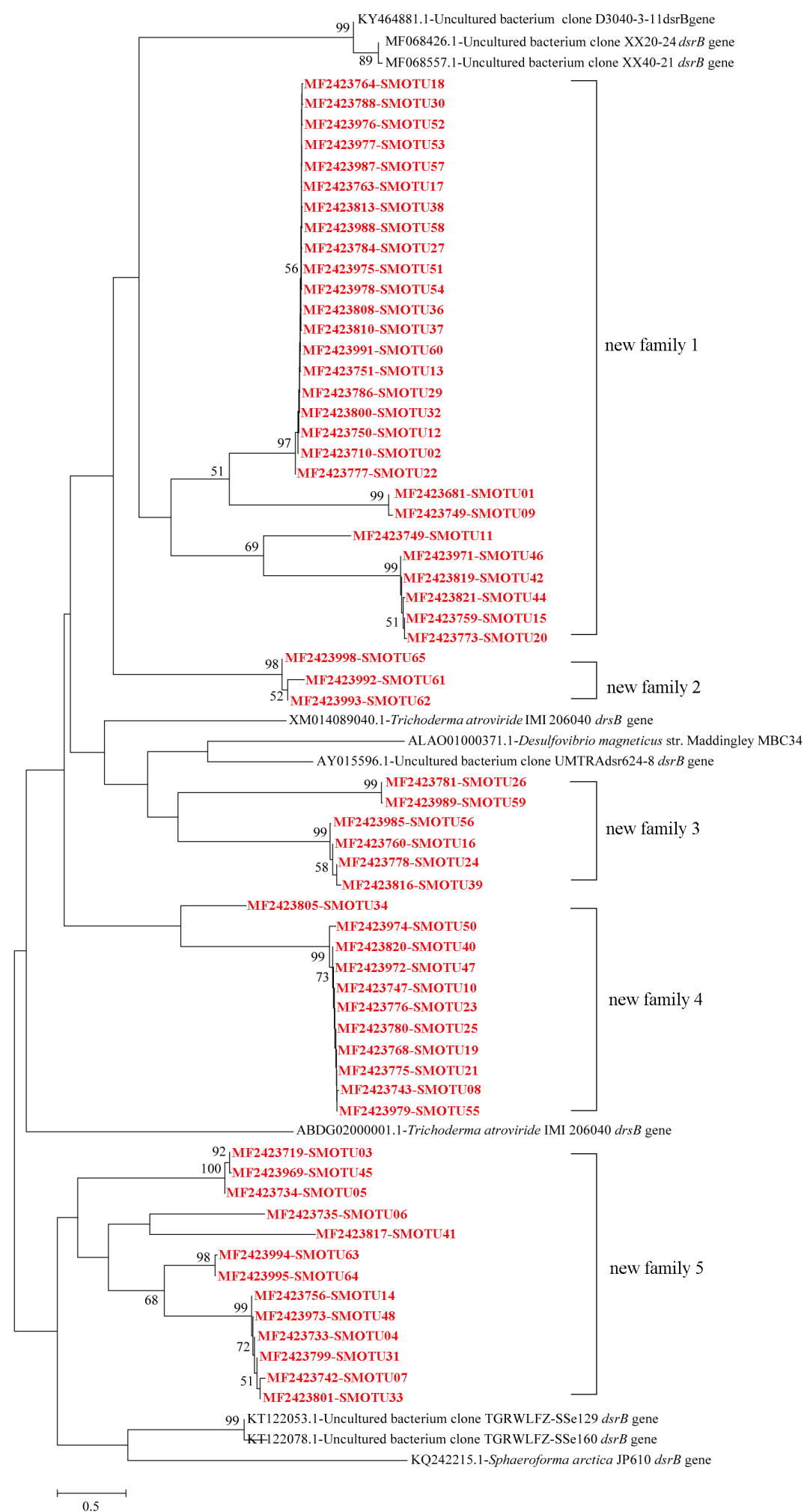

Figure 1

The phylogenetic affiliation of drs $A B$ gene sequences obtained from tailing soils of the Shimen Realgar Mine. 
a

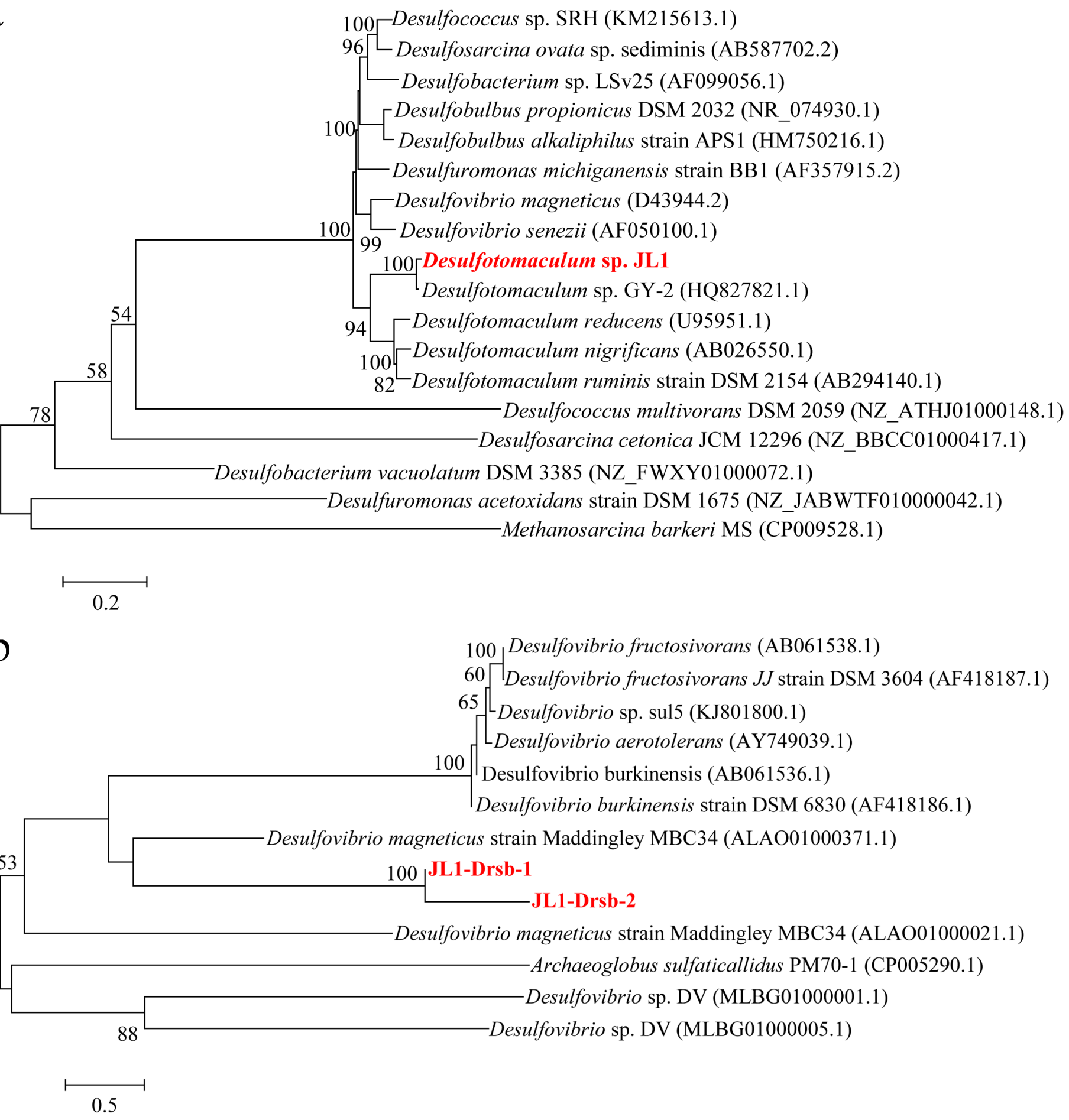

\section{Figure 2}

Cloning and phylogenatic feature of the 16S rRNA (a) and dissimilatory sulfite reductase genes (b) from Desulfotomaculum sp.JL1. The topology of tree was constructed by the the neighbor-joining method. The values at the nodes are boostrap values ( $n=1000$ replicates) of $\geq 50 \%$ are shown. 

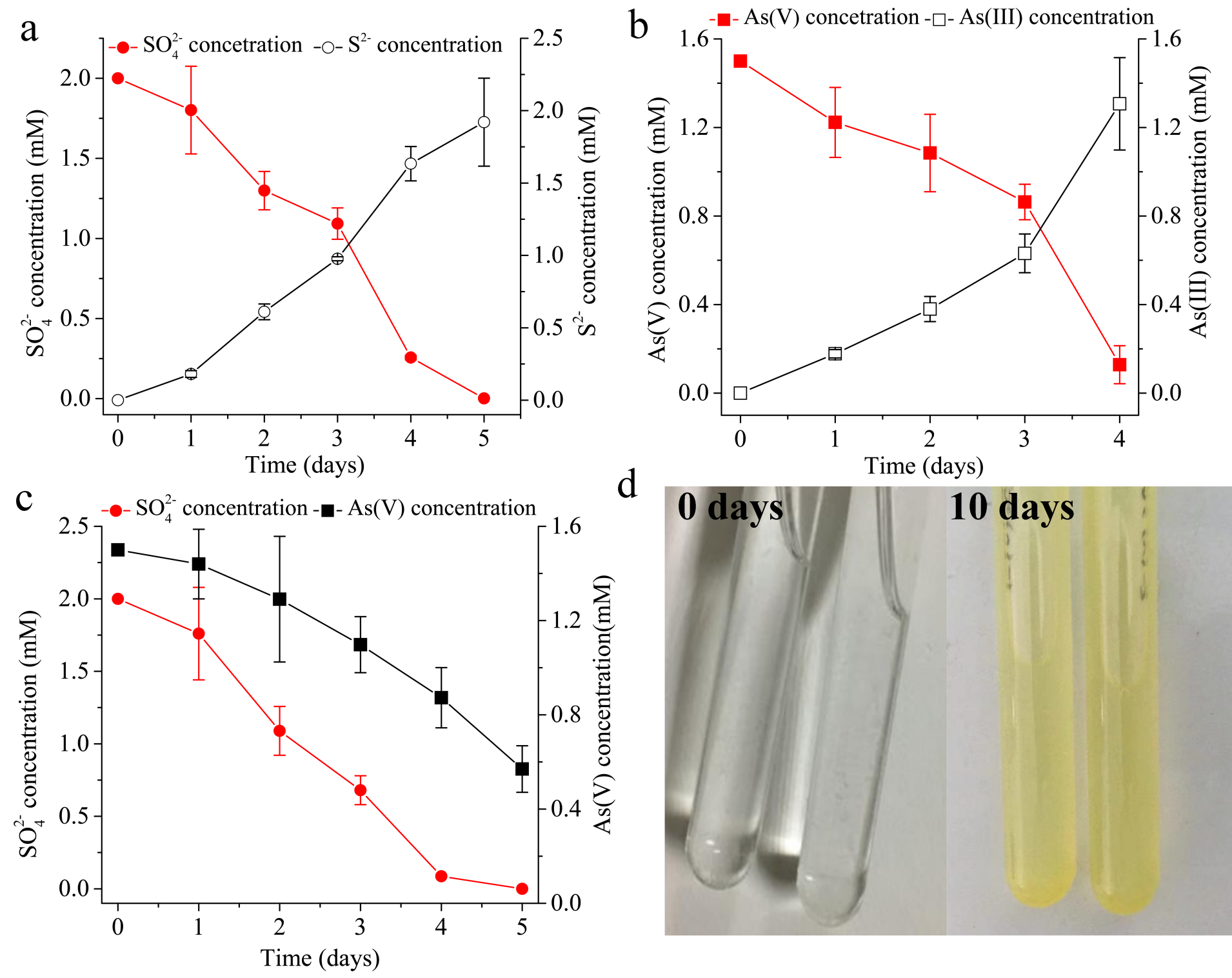

\section{Figure 3}

Functional charaterization of Desulfotomaculum sp. JL01. (a) The sulfate-respiring activities of JL1; (b) The arsenate-respiring activity of JL1; (c) The reduction abilities of JL1 in the presence of multiple electron acceptors ( both contain sulfate ans $A s(V)$ in the cultures). (d) The appearance difference of serum bottle before and after culture. 
a

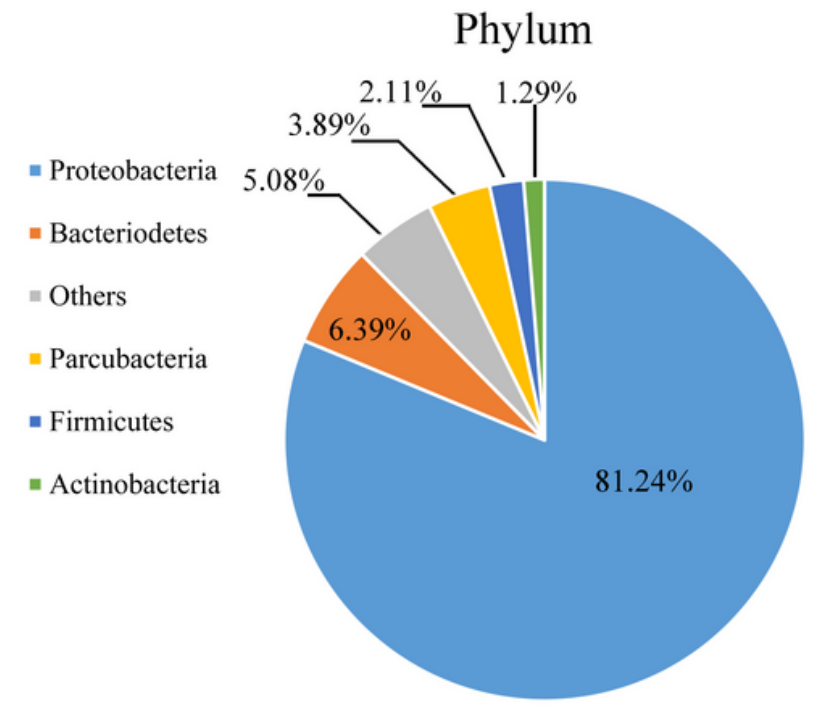

b

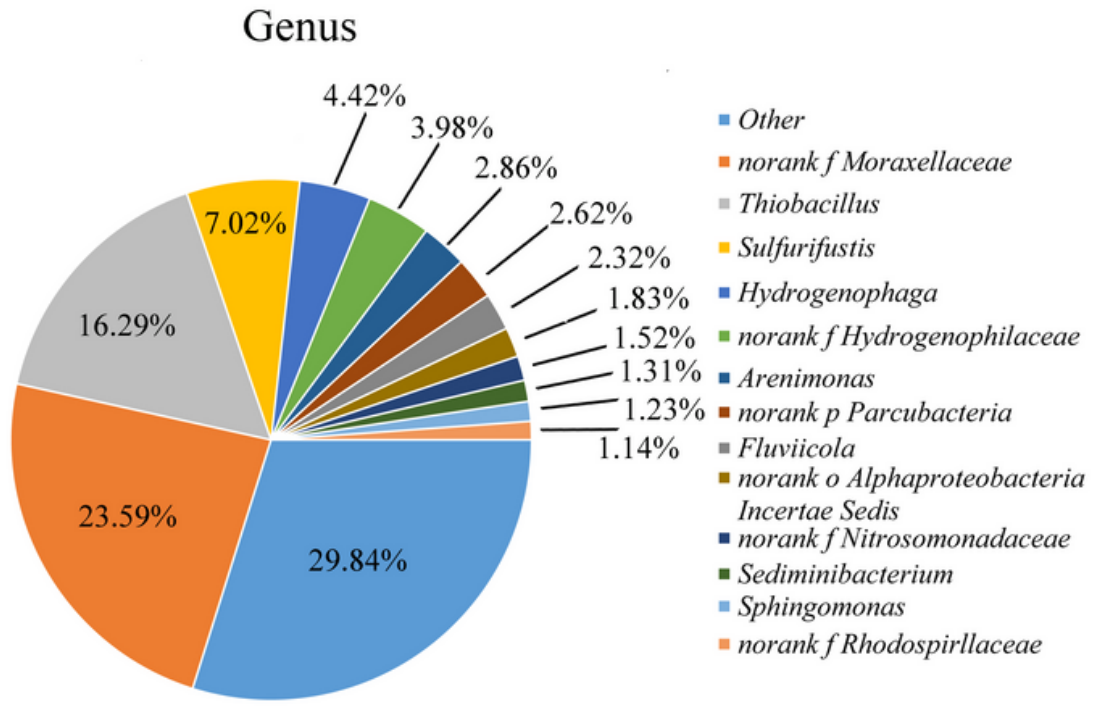

\section{Figure 4}

The microbial community compositions of the soil sample from the Shimen realgar on phylum (a) and genus (b) level.
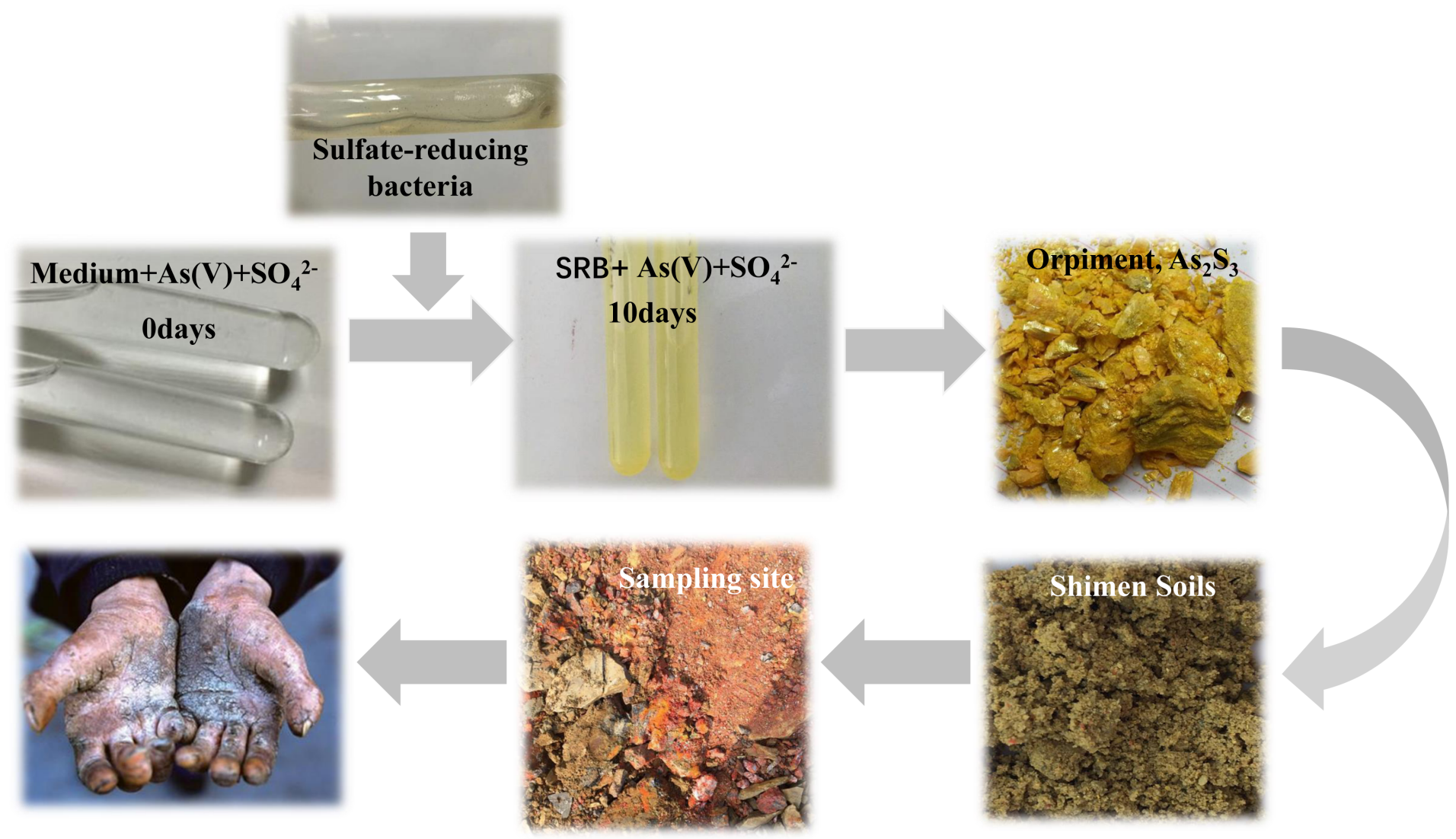

\section{Figure 5}


Conceptual model for the ecological effect of sulfate-reducing bacteria to the Shimen Realgar Mine. 